\title{
Continuous use of low-dose warfarin for gastric endoscopic submucosal dissection: a prospective study
}

\section{(ㄷ)(1) $(9)$}

\section{Authors}

Hideaki Harada', Satoshi Suehiro', Daisuke Murakami', Takanori Shimizu', Ryotaro Nakahara', Yasushi Katsuyama1, Yasunaga Miyama², Shigetaka Tounou ${ }^{3}$, Kenji Hayasaka ${ }^{1}$

\section{Institutions}

1 Department of Gastroenterology, New Tokyo Hospital, Chiba, Japan

2 Department of Health Service Center, Tokyo Medical and Dental University, Tokyo, Japan

3 Second Division of Internal Medicine, Teikyo University Chiba Medical Center, Chiba, Japan

submitted 4.8.2016

accepted after revision $\quad 6.2 .2017$

\author{
Bibliography \\ DOI https://doi.org/10.1055/s-0043-105493 | \\ Endoscopy International Open 2017; 05: E348-E353 \\ (c) Georg Thieme Verlag KG Stuttgart · New York \\ ISSN 2364-3722
}

Corresponding author

Hideaki Harada, MD, Department of Gastroenterology, New Tokyo Hospital, 1271 Wanagaya, Matsudo, Chiba 270-

2232, Japan

Fax: +81-47-392-8718

nerimaendo@hotmail.co.jp

\section{ABSTRACT}

Background and study aims Patients who receive warfarin usually require heparin bridge therapy (HBT) to prevent thromboembolic events during endoscopic submucosal dissection (ESD); however, clinical evidence demonstrating the safety and efficacy of HBT during gastric ESD is limited. Conversely, warfarin can be continuously used as a substitute for HBT to endoscopic procedures which have a low risk of bleeding. This study aimed to clarify the safety and efficacy of continuous low-dose warfarin (LDW) for gastric ESD.

Patients and methods This was a prospective observational study at a single institution. A total of 22 patients who received warfarin between December 2014 and January 2016 were enrolled. The patients were treated with gastric ESD with a low dose of warfarin $(\leq 4 \mathrm{mg}$ ) at approximately $1.6-2.6$ of the international normalized ratio (INR) levels. Furthermore, we analyzed a total of 23 patients with HBT who underwent gastric ESD between January 2011 and November 2014.

Results The average of warfarin dose and the INR level on the day of gastric ESD in the continuous LDW group were $2.3 \mathrm{mg} /$ day (range $0.5-4.0$ ) and 1.87 (range $1.41-2.75$ ), respectively. Two of the 22 patients $(9.1 \%)$ in the continuous LDW group and 5 of the 23 patients $(21.7 \%)$ in the HBT group had postoperative bleeding after gastric ESD. Although the postoperative bleeding rate in the continuous LDW group was lower than that in the HBT group, no significant difference was observed between the 2 groups ( $P=$ 0.414).

Conclusions Gastric ESD with continuous LDW as a substitute for HBT was feasible and may be acceptable.

\section{Introduction}

Endoscopic submucosal dissection (ESD) is widely accepted as a minimally invasive treatment for gastric neoplasms when the risk of lymph node metastasis is minimal [1-4]. The rate of complications such as intraoperative bleeding or a perforation caused by conventional endoscopic mucosal resection (EMR) is less than that of ESD [5]. However, the failure rate of en bloc resection for lesions $>20 \mathrm{~mm}$ in diameter, with or without ulceration, with EMR is significantly higher than that with ESD [5]. An advantage of ESD is that the tumor can be endoscopically resected en bloc regardless of its size or presence of ulceration.
Therefore, ESD is recommended in cases of lesions $\geq 20 \mathrm{~mm}$ in diameter with or without ulceration.

Although considerable expertise is required to perform ESD, incidence of perforations has decreased due to technological advances in various devices, including surgical knives, hemostatic forceps, and high-frequency devices. Proton pump inhibitors (PPIs) and post-ESD coagulation therapy for visible vessels after ESD have been reported to be effective for preventing postoperative bleeding [6, 7]. However, postoperative bleeding is still controversial because prophylactic therapy for post-ESD bleeding has not yet been perfectly established. 
Anticoagulants are used to prevent cerebrovascular and cardiovascular diseases, such as atrial fibrillation (AF), valvular heart disease, or deep vein thrombosis. These drugs must not be discontinued before endoscopic procedures that have a low risk of bleeding, such as diagnostic endoscopy or endoscopic biopsy [1]. However, endoscopic procedures with a high risk of bleeding, such as EMR or ESD, require patients to discontinue anticoagulants or replace them with unfractionated heparin or low-molecular-weight heparin as a bridge therapy based on the European Society of Gastrointestinal Endoscopy (ESGE) and guidelines of the American Society for Gastrointestinal Endoscopy (ASGE) and Japan Gastroenterological Endoscopy Society (JGES) [8-10]. Although patients receiving warfarin usually require heparin bridge therapy (HBT) to prevent thromboembolic events during ESD, clinical data that confirm its safety and efficacy are limited $[11,12]$.

ESGE, ASGE and JGES guidelines advocate continuous use of warfarin in patients who undergo endoscopic procedures are associated with a low risk of bleeding, such as esophagoduodenoscopy (EGD), colonoscopy, or mucosal biopsy [8-10]. Some studies have recently reported that patients who were receiving warfarin underwent colonic polypectomy [13-15]. However, there are no reports on the clinical outcomes of bleeding after gastric ESD in patients who were receiving continuous warfarin. Herein, we report clinical outcomes after gastric ESD in patients with continuous use of low-dose warfarin (LDW).

\section{Patients and methods}

This was a prospective observational study and single-center evaluation. From December 2014 to January 2016, 22 patients receiving warfarin who were scheduled to be treated with gastric ESD were enrolled. The patients were treated with gastric ESD with a low dose of warfarin $(\leq 4 \mathrm{mg})$. The ethics committee of the New Tokyo Hospital approved the study protocol (IRB No. NTH 2014-12-11-0069). We also analyzed 23 patients with HBT who underwent gastric ESD from January 2011 to November 2014 ( Fig. 1). To evaluate the feasibility of gastric ESD with continuous LDW, we compared outcomes of gastric ESD between the continuous LDW group and the HBT group. All patients provided written informed consent before enrollment. The treatment indication for these patients was based on guidelines proposed by the Japanese Gastric Cancer Association and included the expanded criteria proposed by Gotoda et al [16].

Patient clinical records were reviewed after obtaining approval from the institutional review board of the New Tokyo Hospital.

\section{ESD procedure}

ESD was performed with either a single-channel endoscope or a 2-channel endoscope (GIF-Q260J, GIF-H290Z, and GIF2TQ260M; Olympus, Tokyo, Japan). We used either a FlushKnife BT (DK2618JB; Fujifilm, Tokyo, Japan) or a DualKnife (KD-650L; Olympus, Tokyo, Japan) as the electrosurgical knife, and applied an electrosurgical current to the knife with an electrosurgical generator (VIO300D; ERBE, Tübingen, Germany). After detecting the lesion, markings were made around the lesion using the
Patients with warfarin who underwent gastric ESD between January 2011 and January $2016(n=45)$

Heparin bridge therapy between January 2011 and November 2014 $(n=23)$ Continous LDW between December 2014 and January 2016 $(n=22)$

- Fig. 1 Flowchart of inclusions and exclusions criteria for this study. ESD, endoscopic submucosal dissection; LDW, low-dose warfarin.

electrosurgical knife. Sodium hyaluronate was injected into the submucosal layer. The circumferential mucosal incisions outside the markings were made with the electrosurgical knife and the submucosa of the lesion was dissected. Prophylactic coagulation was performed on exposed vessels using hemostatic forceps (FD-230U or FD-410LR; Olympus, Tokyo, Japan) during the submucosal dissection. Once the lesion was removed, all visible vessels on the artificial ulcer bed were coagulated with hemostatic forceps.

\section{Management of patients receiving anticoagulation}

Patients who were diagnosed as having a high risk for thrombosis were treated with uninterrupted warfarin. High risk for thrombosis was defined based on ASGE guidelines and a $\mathrm{CHADS}_{2}$ score as follows: patients with AF associated with valvular heart disease (whether surgically corrected or not), mechanical valves in the mitral position, mechanical valves in patients who have had a previous thromboembolic event, and a $\mathrm{CHADS}_{2}$ score $>2$ (chronic heart failure, hypertension, aged $>75$ years, diabetes mellitus, or a stroke) [17-19]. We also consulted with the prescribing physician before the procedure to determine whether warfarin should be stopped or adjusted.

In patients on continuous LDW, we performed ESD with international normalized ratio (INR) levels at approximately 1.6 2.6 using LDW during the periendoscopic period based on Japanese guidelines [20 - 23]. We checked the INR levels a week before ESD. If the INR levels were $\geq 2.6$ a week before ESD, we changed the warfarin dose to a low dose in the outpatient clinic. All patients were hospitalized a day before ESD, and INR levels were assessed on the day of ESD. INR levels were also assessed the day after ESD and 3 days after ESD. If INR levels were $\geq 3.0$, vitamin $K$ was used to control the INR levels. If a patient was bleeding after gastric ESD, warfarin was discontinued temporarily. Once no bleeding was confirmed the day after EGD, warfarin was restarted.

In HBT patients, heparin was administered continuously while the activated partial thromboplastin was maintained at approximately twice the preheparinization level after warfarin was discontinued. Furthermore, the INR was measured on the day of ESD and the patient was treated after confirming that the effect of warfarin had almost disappeared (INR $\leq 1.5)$. Heparin was administered up to $4-6 \mathrm{~h}$ before ESD and restarted $4 \mathrm{~h}$ after ESD. Once no bleeding was confirmed the day after EGD, warfarin was restarted in patients with HBT. In patients re- 
- Table 1 Clinical findings of gastric neoplasms resected by ESD between continuous LDW and heparin bridge therapy: baseline demographic data.

\begin{tabular}{|c|c|c|c|}
\hline & $\begin{array}{l}\text { Continuous LDW } \\
(\mathrm{n}=\mathbf{2 2})\end{array}$ & $\begin{array}{l}\text { Heparin bridge therapy } \\
(\mathrm{n}=23)\end{array}$ & $P$ value \\
\hline Age, mean (SD), years & $76.8(6.0)$ & 72.7 (7.9) & 0.057 \\
\hline Male sex, n (\%) & $19(86.4)$ & $21(91.3)$ & 0.665 \\
\hline Comorbidities, $\mathrm{n}(\%)^{1}$ & $22(100)$ & $21(91.3)$ & 0.489 \\
\hline Antiplatelet therapy, n (\%) & $11(50.0)$ & $10(47.6)$ & 0.768 \\
\hline INR, mean (SD) & $1.85(0.4)$ & $1.26(0.1)$ & $<0.001$ \\
\hline $\mathrm{CHADS}_{2}$ score, mean $(\mathrm{SD})^{2}$ & $2.9(0.4)$ & $1.7(1.0)$ & $<0.001$ \\
\hline Tumor location, n (\%) & & & 0.779 \\
\hline - Upper & $5(22.7)$ & $4(17.4)$ & \\
\hline - Middle & $6(27.3)$ & $5(21.7)$ & \\
\hline - Lower & $11(50.0)$ & $14(60.9)$ & \\
\hline \multicolumn{4}{|c|}{$\begin{array}{l}\text { ESD, endoscopic submucosal dissection; LDW, low-dose warfarin; SD, standard deviation; INR, international normalization ratio. } \\
{ }^{1} \text { Comorbidities indicate current diseases (hypertension, diabetes mellitus, chronic renal failure, or liver cirrhosis). } \\
{ }^{2} \mathrm{CHADS}_{2} \text { score indicates the risk of stroke with regards to atrial fibrillation. }\end{array}$} \\
\hline
\end{tabular}

quiring endoscopic hemostasis for multiple visible vessels during second-look endoscopy, warfarin was restarted after thirdlook endoscopy. After giving warfarin to HBT patients, heparin was continued until therapeutic INR levels (approximately 1.6 2.6) were achieved.

\section{Treatment after ESD}

PPIs were administered intravenously for 2 days following the procedure. Second-look endoscopy was performed on all patients the day after ESD. If vessels in the ulcer bed were observed, we performed coagulation with hemostatic forceps. Once it was confirmed that there were no signs of postoperative bleeding, a liquid diet with oral administration of PPI was started 2 days after ESD. PPIs were administered to all patients for 8 weeks after ESD.

Patients not receiving anticoagulants were usually discharged approximately 5 days after ESD if they had no complications. Patients receiving continuous LDW who had no signs of bleeding after ESD were usually discharged within 5-7 days. Patients receiving HBT were discharged after confirming that they had no signs of bleeding and their therapeutic INR level was checked after recommencement of warfarin was achieved.

\section{Postoperative bleeding}

Postoperative bleeding was defined as incidence of hematemesis and melena or decrease in blood hemoglobin $(\mathrm{Hb})$ levels $\geq$ $2 \mathrm{mg} / \mathrm{dL}$ and simultaneously requiring endoscopic hemostasis. All patients with hematemesis and melena had emergency EGD and endoscopic hemostasis was performed. If bleeding and decreased $\mathrm{Hb}$ levels were excessive, we performed blood transfusion. Second-look endoscopy was performed on all patients the day after the endoscopic hemostasis.

\section{Outcome measurements}

The main outcome of this study was to investigate postoperative bleeding after gastric ESD in patients with continuous LDW. We also investigated postoperative bleeding compared with HBT.

\section{Statistical analysis}

Categorical variables were compared using chi-squared test or Fisher's exact test, and continuous variables were compared using Student's $t$ test. A $P$ value $<0.05$ was considered statistically significant. All data analyses were conducted using SPSS version 22.0 (IBM Corp., Armonk, NY, USA).

\section{Results}

Patient demographic data between continuous LDW and HBT are shown in $>$ Table 1 . Twenty-two patients receiving continuous LDW were treated with ESD in the study. On the other hand, there were 23 patients received HBT. The mean $\mathrm{CHADS}_{2}$ score in the continuous LDW group was higher than that in the HBT group $(P<0.001)$. The mean INR in the continuous LDW group was also higher than that in the HBT group $(P<0.001)$. There were no significant differences between the 2 groups in terms of age, sex, comorbidities, antiplatelet therapy, and tumor location.

Clinical outcomes between continuous LDW and HBT are shown in $>$ Table 2 . The mean specimen size in the continuous LDW group was smaller than that in the HBT group; however there was no significant difference between the 2 groups $(P=$ 0.099). The mean operation time in the continuous LDW group was lesser than that in the HBT group $(P=0.004)$. Two of the 22 patients $(9.1 \%)$ in the continuous LDW group and 5 of the 23 patients $(21.7 \%)$ in the HBT group had postoperative bleeding after gastric ESD. Although the rate of postoperative bleeding 
- Table2 Clinical outcomes of gastric neoplasms resected by ESD between continuous LDW and heparin bridge therapy.

\begin{tabular}{|c|c|c|c|}
\hline & $\begin{array}{l}\text { Continuous LDW } \\
(n=22)\end{array}$ & $\begin{array}{l}\text { Heparin bridge therapy } \\
(n=23)\end{array}$ & $P$ value \\
\hline Specimen size, mean (SD), mm & $30.6(8.3)$ & $36.2(13.1)$ & 0.099 \\
\hline Pathological findings, $\mathrm{n}(\%)^{1}$ & & & 0.974 \\
\hline - Differentiated & $21(95.2)$ & $22(95.7)$ & \\
\hline - Undifferentiated & $1(4.8)$ & $1(4.3)$ & \\
\hline Bleeding rate, $\mathrm{n}(\%)$ & $2(9.1)$ & $5(21.7)$ & 0.414 \\
\hline Operation time, mean (SD), minutes & $40.4(18.3)$ & $79.3(57.4)$ & 0.004 \\
\hline Hospitalization, mean (SD), days & $7.5(4.8)$ & $14.2(3.3)$ & $<0.001$ \\
\hline
\end{tabular}

in the continuous LDW group was lower than that in the HBT group, no significant difference was observed between the 2 groups $(P=0.414)$. The average length of hospitalization in the continuous warfarin group ( $7.5 \pm 4.8$ days) was almost identical to that in the group that received no anticoagulation therapy (7.4 \pm 2.6 days); the length of hospitalization in the HBT group was $14.2 \pm 3.3$ days.

Clinical and endoscopic characteristics of patients on continuous LDW are shown in $>$ Table 3 . The average warfarin dose that patients received was $2.3 \mathrm{mg} /$ day (range $0.5-4.0$ ). The INR level averaged 1.87 (range $1.41-2.75$ ) on the day of ESD.

\section{Postoperative bleeding}

Postoperative bleeding started later in the HBT group compared with the continuous LDW group. Postoperative bleeding was observed on Days 2 and 4 in the continuous LDW group, and on days 4, 5, and 7 in the HBT group. Postoperative bleeding was sparse in patients not taking any anticoagulant and was observed between days 0 and 12 . All bleeding events were successfully managed with endoscopic hemostasis.

\section{Discussion}

This study investigated postoperative outcomes after gastric ESD in patients receiving continuous LDW. Although the results showed that the rate of postoperative bleeding in the continuous LDW group was lower than that in the HBT group, there was no significant difference between the 2 groups $(P=0.414)$. The average length of hospitalization in the continuous LDW group was almost half that in the HBT group because continuous heparin was given IV during hospitalization 3-5 days before ESD, and HBT patients were discharged after confirmation that their therapeutic INR level had been achieved after recommencement of warfarin.

A recent retrospective study reported on HBT in high-risk patients who underwent ESD [11]. The authors showed that there was a higher frequency of delayed bleeding after ESD in the HBT group compared with the control group (no anticoagulant therapy). The delayed bleeding rate was $37.5 \%$ in the HBT group and only $4.8 \%$ in the control group. Moreover, the study showed that the average period of postoperative bleeding in the HBT group was $8.0 \pm 5.7$ days versus $3.8 \pm 4.1$ days for the control group [11]. Our study showed that postoperative bleeding started later in the HBT group compared with that in the continuous LDW group. Postoperative bleeding was observed on Days 2 and 4 in the continuous LDW group and on Days 4, 5, and 7 in the HBT group. Why did this discrepancy occur between the 2 groups? Presumably, the double effect of heparin and warfarin after recommencement of warfarin caused delayed bleeding after ESD in the previous study. Our study shows that delayed bleeding of HBT occurred approximately 5-7 days after ESD, simultaneous with the action of warfarin. The discrepancy in the previous study likely was for the same reason.

In this study, we performed gastric ESD with low-dose warfarin to maintain the INR level at approximately 1.6-2.6. Relevant studies have shown that an INR level between 1.6 and 1.9 is sufficiently effective for anticoagulation in Japanese patients with nonvalvular AF (NVAF) [20]. Moreover, this study has shown that bleeding complications associated with warfarin were increased to levels $>2.6$ in older Japanese patients with NVAF [20]. INR levels in older Japanese patients who had AF associated with valvular diseases were appropriately maintained at approximately $1.6-2.2$, and those who had AF after an artificial heart valve replacement were appropriately maintained at approximately $2.0-2.5$, based on Japanese guidelines $[21,22]$. Therefore, the target INR during the periendoscopic period was within 1.6-2.6 in this study. Effective INR levels in Japanese patients have been reported to differ from those in patients in Western countries [23]. In Western countries, maintenance of INR levels between 2.0 and 3.0 is recommended, irrespective of diagnosis [24]. Therefore, our target INR range may not necessarily apply to all ethnic groups.

The INR level in the continuous LDW group averaged 1.87 (range $1.41-2.75$ ) on the day of ESD and was successfully controlled. The average INR level the day after ESD was 1.94 (range $1.47-3.11$ ) and was 2.08 (range 1.32 -3.04) 3 days after ESD. The INR levels of 2 patients who suffered postoperative bleed- 
- Table 3 Clinical and endoscopic features of patients with continuous LDW for gastric ESD.

\begin{tabular}{|c|c|c|c|c|c|c|c|c|c|c|c|c|}
\hline $\begin{array}{l}\text { Case } \\
\text { no. }\end{array}$ & $\begin{array}{l}\text { Age, } \\
\text { Sex } \\
(M / F)\end{array}$ & $\begin{array}{l}\text { Post- } \\
\text { opera- } \\
\text { tive } \\
\text { bleed- } \\
\text { ing }\end{array}$ & $\begin{array}{l}\text { Tumor } \\
\text { location } \\
\text { (U/M/L) }\end{array}$ & $\begin{array}{l}\text { Speci- } \\
\text { men } \\
\text { size } \\
(\mathrm{mm})\end{array}$ & $\begin{array}{l}\text { Opera- } \\
\text { tion } \\
\text { time } \\
\text { (min- } \\
\text { utes) }\end{array}$ & $\begin{array}{l}\text { Dose } \\
\text { of } \\
\text { war- } \\
\text { farin } \\
\text { (mg) }\end{array}$ & $\begin{array}{l}\text { INR } \\
\text { (OPOD) }\end{array}$ & $\begin{array}{l}\text { INR } \\
\text { (1POD) }\end{array}$ & $\begin{array}{l}\text { INR } \\
\text { (3POD) }\end{array}$ & $\begin{array}{l}\text { Anti- } \\
\text { plate- } \\
\text { let } \\
\text { drugs }\end{array}$ & $\begin{array}{l}\text { Comor- } \\
\text { bidities }\end{array}$ & $\begin{array}{l}\text { CHADS }_{2} \\
\text { score }^{1}\end{array}$ \\
\hline 1 & $65, M$ & - & U & 12 & 20 & 3.0 & 1.67 & 1.68 & 1.73 & + & HT & 2 \\
\hline 2 & $86, \mathrm{M}$ & - & U & 18 & 33 & 2.5 & 2.16 & 1.93 & 1.83 & + & DM & 3 \\
\hline 3 & $71, \mathrm{M}$ & + & M & 35 & 45 & 0.5 & 1.42 & 1.47 & 1.58 & + & $\mathrm{HT}, \mathrm{RF}$ & 4 \\
\hline 4 & $72, F$ & - & M & 28 & 23 & 1.5 & 1.53 & 1.87 & 2.11 & - & HT, DM & 2 \\
\hline 5 & $79, \mathrm{M}$ & - & U & 43 & 82 & 3.0 & 1.55 & 1.68 & 1.96 & - & HT, DM & 3 \\
\hline 6 & $82, \mathrm{~F}$ & - & M & 25 & 41 & 2.0 & 1.79 & 1.67 & 1.32 & - & HT & 2 \\
\hline 7 & $71, \mathrm{M}$ & - & $\mathrm{L}$ & 31 & 26 & 2.0 & 1.41 & 1.47 & 1.77 & + & DM & 3 \\
\hline 8 & $82, \mathrm{M}$ & + & L & 38 & 78 & 2.0 & 2.04 & 1.88 & 2.48 & + & HT, DM & 3 \\
\hline 9 & $80, \mathrm{M}$ & - & M & 32 & 39 & 2.5 & 2.47 & 2.15 & 1.70 & + & DM & 3 \\
\hline 10 & $72, \mathrm{M}$ & - & L & 45 & 68 & 2.0 & 1.50 & 1.46 & 2.13 & + & HT, DM & 3 \\
\hline 11 & $73, \mathrm{M}$ & - & M & 25 & 33 & 3.0 & 1.42 & 1.49 & 1.80 & + & HT & 3 \\
\hline 12 & $83, \mathrm{M}$ & - & $\mathrm{L}$ & 31 & 23 & 4.0 & 1.97 & 2.12 & 2.47 & + & HT, DM & 3 \\
\hline 13 & $77, \mathrm{M}$ & - & $\mathrm{L}$ & 40 & 36 & 2.5 & 1.94 & 2.11 & 1.85 & - & HT & 2 \\
\hline 14 & $82, \mathrm{M}$ & - & M & 25 & 26 & 2.0 & 1.54 & 1.80 & 3.04 & - & HT, DM & 3 \\
\hline 15 & $71, \mathrm{M}$ & - & $\mathrm{L}$ & 30 & 22 & 1.5 & 2.75 & 3.11 & 2.57 & - & $\mathrm{HT}, \mathrm{RF}$ & 2 \\
\hline 16 & $82, \mathrm{~F}$ & - & $\mathrm{L}$ & 42 & 41 & 2.5 & 1.97 & 1.86 & 2.49 & - & HT & 3 \\
\hline 17 & $79, \mathrm{M}$ & - & $\mathrm{L}$ & 34 & 58 & 2.0 & 1.94 & 2.18 & 1.85 & - & HT, DM & 3 \\
\hline 18 & $69, \mathrm{M}$ & - & $\mathrm{L}$ & 20 & 21 & 2.0 & 1.78 & 2.03 & 2.30 & - & HT, DM & 2 \\
\hline 19 & $74, \mathrm{M}$ & - & U & 28 & 52 & 3.0 & 2.35 & 2.78 & 2.52 & + & HT, DM & 3 \\
\hline 20 & 79, M & - & $\mathrm{L}$ & 31 & 44 & 2.0 & 1.95 & 2.10 & 2.28 & - & HT & 3 \\
\hline 21 & $88, \mathrm{M}$ & - & $\mathrm{L}$ & 35 & 26 & 3.5 & 1.80 & 1.80 & 1.82 & - & HT, DM & 3 \\
\hline 22 & $73, M$ & - & U & 26 & 52 & 2.0 & 2.08 & 2.11 & 2.25 & + & HT, DM & 3 \\
\hline
\end{tabular}

ing in the continuous LDW group ranged from 1.6 to 2.6 during the periendoscopic period. One patient was on antiplatelet therapy (discontinuation of ticlopidine for 5 days before ESD) and had a longer operation time whereas the other had renal failure, was on antiplatelet therapy (discontinuation of clopidogrel for 5 days before ESD), and had a high $\mathrm{CHADS}_{2}$ score (4 points). It appeared that the risk of postoperative bleeding in these two patients was higher than that in other patients.

In addition to anticoagulation therapy, previous studies present antiplatelet therapy as one of the independent risk factors for postoperative bleeding after gastric ESD. Current guidelines recommend continuation of low-dose aspirin in patients with high-risk of thrombosis who undergo ESD [8-10]. In particular, continuing low-dose aspirin or thienopyridine is mandatory to prevent thrombosis in patients receiving dual antiplatelet therapy (aspirin plus thienopyridine) who undergo
ESD [8]. At our hospital, thienopyridine was usually discontinued in patients who underwent ESD. Because data are lacking on continuous use of thienopyridine, further study will be needed in the future.

It is our opinion that continuous LDW is better than HBT for controlling hemorrhage during ESD. While there was no excessive bleeding associated with continuous LDW during ESD, there were 2 HBT patients in whom it was difficult to control bleeding during ESD. These 2 patients needed frequent endoscopic hemostasis with hemostatic forceps during ESD; the bleeding was eventually controlled. We have not had any cases of thromboembolic events in patients who were receiving warfarin during the periendoscopic period. Even though 1 patient on continuous LDW had a cerebral infarction 3 months after ESD, it was found to be caused by the patient not receiving warfarin properly after discharge from the hospital. 
This study has several limitations. First, it was a single-center analysis and not randomized. Second, the comparison with continuous LDW and HBT could have been influenced by a selection bias. The mean $\mathrm{CHADS}_{2}$ score in the continuous LDW group was higher than that in the HBT group. Furthermore, the mean operation time in the continuous LDW group was less than that in the HBT group, and the mean specimen size in the continuous LDW group was smaller than that in the HBT group. In this study, the comparison with continuous LDW and HBT may not be adequate because of confounding variables. Therefore, it remains unclear whether continuous LDW causes less bleeding than HBT.

\section{Conclusion}

In conclusion, gastric ESD with continuous LDW as a substitute for HBT was feasible and may be acceptable. A further prospective, randomized study will be needed in the future.

\section{Acknowledgements}

We would like to thank Dr. S. Nakamura at the New Tokyo Hospital for valuable comments and assistance.

\section{Competing interests}

None

\section{References}

[1] Miyamoto S, Muto M, Hamamoto $Y$ et al. A new technique for endoscopic mucosal resection with an insulated-tip electrosurgical knife improves the completeness of resection of intramucosal gastric neoplasms. Gastrointest Endosc 2002; 55: 576-581

[2] Yamamoto H, Kawata H, Sunada K et al. Success rate of curative endoscopic mucosal resection with circumferential mucosal incision assisted by submucosal injection of sodium hyaluronate. Gastrointest Endosc 2002; 56: 507 - 512

[3] Yahagi N, Fujishiro M, Kakushima N et al. Endoscopic submucosal dissection for early gastric cancer using the tip of an electrosurgical snare (thin type). Dig Endosc 2004; 16: 34-38

[4] Oda I, Gotoda T, Hamanaka H et al. Endoscopic submucosal dissection for early gastric cancer: technical feasibility, operation time and complications from a large consecutive series. Dig Endosc 2005; 17 : $54-58$

[5] Oka S, Tanaka S, Kaneko I et al. Advantage of endoscopic submucosal dissection compared with EMR for early gastric cancer. Gastrointest Endosc 2006; 64: 877-883

[6] Uedo N, Takeuchi Y, Yamada T et al. Effect of a proton pump inhibitor or an $\mathrm{H} 2$-receptor antagonist on prevention of bleeding from ulcer after endoscopic submucosal dissection of early gastric cancer: a prospective randomized controlled trial. Am J Gastroenterol 2007; 102: $1610-1616$

[7] Takizawa K, Oda I, Gotoda T et al. Routine coagulation of visible vessels may prevent delayed bleeding after endoscopic submucosal dissection-an analysis of risk factors. Endoscopy 2008; 40: 179-183

[8] Veitch AM, Vanbiervliet G, Gershlick AH et al. Endoscopy in patients on antiplatelet or anticoagulant therapy, including direct oral anticoagulants: British Society of Gastroenterology (BSG) and European
Society of Gastrointestinal Endoscopy (ESGE) Guidelines. Endoscoy 2016; 48: 385-402

[9] Anderson MA, Ben-Menachem T, Gan SI et al. Guideline: management of antithrombotic agents for endoscopic procedures. Gastrointest Endosc 2009; 70: 1060 - 1070

[10] Fujimoto K, Fujishiro M, Kato M et al. Guidelines for gastroenterological endoscopy in patients undergoing antithrombotic treatment. Dig Endosc 2014; 26: 1 - 14

[11] Yoshio T, Nishida T, Kawai N et al. Gastric ESD under Heparin Replacement at High-Risk Patients of Thromboembolism Is Technically Feasible but Has a High Risk of Delayed Bleeding: Osaka University ESD Study Group. Gastroenterol Res Pract 2013; 2013: 365830

[12] Matsumura T, Arai M, Maruoka D et al. Risks factors for early and delayed post-operative bleeding after endoscopic submucosal dissection of gastric neoplasms, including patients with continued use of antithrombotic agents. BMC Gastroenterol 2014; 14: 172

[13] Choudari CP, Rajgopal C, Palmer KR. Acute gastrointestinal haemorrhage in anticoagulated patients: Diagnoses and response to endoscopic treatment. Gut 1994; 35: $464-466$

[14] Aric J, Wong RMY, Ching JYL et al. Risk of colonoscopic polypectomy bleeding with anticoagulants and antiplatelet agents: analysis of 1657 cases. Gastrointest Endosc 2004; 59: 44 - 48

[15] Horiuchi A, Nakayama Y, Kajiyama M et al. Removal of small colorectal polyps in anticoagulated patients: a prospective randomized comparison of cold snare and conventional polypectomy. Gastrointest Endosc 2014; 79: 417-423

[16] Gotoda T, Yanagisawa A, Sasako M et al. Incidence of lymph node metastasis from early gastric cancer: estimation with a large number of cases at two large centers. Gastric Cancer 2000; 3: 219-225

[17] Gage BF, Waterman AD, Shannon W et al. Validation of clinical classification schemes for predictng stroke: results from the National Registry of Atrial Fibrillation. JAMA 2001; 285: 2864-2870

[18] Go AS, Hylek EM, Chang Y et al. Anticoagulation therapy for stroke prevention in atrial fibrillation: how well do randomized trials translate into clinical practice? JAMA 2003; 290: 2685-2692

[19] Goldstein LB, Adams R, Alberts M] et al. Primary prevention of ischemic stroke: a guideline from the American Heart Association/ American Stroke Association Stroke Council: cosponsored by the Atherosclerotic Peripheral Vascular Disease Interdisciplinary Working Group; Cardiovascular Nursing Council; Clinical Cardiology Council; Nuitrition, Physical Activity, and Metabolism Council; and the Quality of Care and Outcomes Research Interdisciplinary Working Group: the American Academy of Neurology affirms the value of this guideline. Stroke 2006; 37: 1583-1633

[20] Yasaka M, Minematsu K, Yamaguchi T. Optimal intensity of international normalized ratio in warfarin therapy for secondary prevention of stroke in patients with non-valvular atrial fibrillation. Int Med 2001; 40: $1183-1188$

[21] Murasaki K. Guidelines for management of anticoagulant and antiplatelet therapy in cardiovascular disease (JCS 2009). Nihon Rinsho 2011; 69: $567-571$

[22] Mori T, Asano M, Ohtake $\mathrm{H}$ et al. Anticoagulation therapy after prosthetic valve replacement-optimal PT-INR in Japanese patients. Ann Thorac Cardiovasc Surg 2002; 8: 83-87

[23] Yamaguchi T. Optimal intensity of warfarin therapy for secondary prevention of stroke in patients with nonvalvular atrial fibrillation: a multicenter, prospective, randomized trial. Japanese Nonvalvular Atrial Fibrillation-Embolism Secondary Prevention Cooperative Study Group. Stroke 2000; 31: 817-821

[24] Anderson JL, Halperin JL, Albert NM et al. Management of patients with atrial fibrillation (compilation of 2006 ACCF/AHA/ESC and 2011 ACCF/AHA/HRS recommendations): a report of the American College of Cardiolorgy/American Heart Association Task Force on Practice Guidelines. J Am Coll Cardiol 2013; 61: 1935 - 1944 